\title{
Psychosis prevalence and physical, metabolic and cognitive co-morbidity: data from the second Australian national survey of psychosis
}

\author{
V. A. Morgan ${ }^{1,2 *}$, J. J. McGrath ${ }^{3,4}$, A. Jablensky ${ }^{2}$, J. C. Badcock ${ }^{5,6}$, A. Waterreus ${ }^{1}$, R. Bush ${ }^{7}$, V. Carr ${ }^{8,9}$, \\ D. Castle ${ }^{10,11}$, M. Cohen ${ }^{12,13}$, C. Galletly ${ }^{14,15,16}$, C. Harvey ${ }^{10,17}$, B. Hocking ${ }^{18}$, P. McGorry ${ }^{10,19,20}$, \\ A. L. Neil ${ }^{21}$, S. Saw ${ }^{22}$, S. Shah ${ }^{1}$, H. J. Stain ${ }^{23,24}$ and A. Mackinnon ${ }^{19,20}$ \\ ${ }^{1}$ Neuropsychiatric Epidemiology Research Unit, School of Psychiatry and Clinical Neurosciences, The University of Western Australia, \\ Crawley, WA, Australia; ${ }^{2}$ Centre for Clinical Research in Neuropsychiatry, School of Psychiatry and Clinical Neurosciences, The University of \\ Western Australia, Crawley, WA, Australia; ${ }^{3}$ Queensland Brain Institute, The University of Queensland, Brisbane, QLD, Australia; ${ }^{4}$ Queensland \\ Centre for Mental Health Research, Brisbane, QLD, Australia; ${ }^{5}$ School of Psychology, The University of Western Australia, Crawley, Western \\ Australia; ${ }^{6}$ Clinical Research Centre, North Metropolitan Health Service-Mental Health, Mount Claremont, WA, Australia; ${ }^{7}$ School of \\ Population Health, The University of Queensland, Ipswich, QLD, Australia; ${ }^{8}$ School of Psychiatry, The University of New South Wales, Sydney, \\ NSW, Australia; ${ }^{9}$ Schizophrenia Research Institute, Sydney, NSW, Australia; ${ }^{10}$ Department of Psychiatry, The University of Melbourne, \\ Melbourne, VIC, Australia; ${ }^{11}$ St Vincent's Hospital, Melbourne, VIC, Australia; ${ }^{12}$ Hunter New England Mental Health, Newcastle, NSW, \\ Australia; ${ }^{13}$ School of Medicine and Public Health, The University of Newcastle, Newcastle, NSW, Australia; ${ }^{14}$ School of Medicine, \\ University of Adelaide, Adelaide, SA, Australia; ${ }^{15}$ Ramsay Health Care (SA) Mental Health Services, Adelaide, SA, Australia; ${ }^{16}$ Northern \\ Sector, Adelaide Metro Mental Health Directorate, Adelaide, SA, Australia; ${ }^{17}$ Psychosocial Research Centre, North West Area Mental Health \\ Services, Coburg, VIC, Australia; ${ }^{18}$ SANE Australia, Melbourne, VIC, Australia; ${ }^{19}$ Orygen Youth Health Research Centre, Melbourne, VIC, \\ Australia; ${ }^{20}$ Centre for Youth Mental Health, The University of Melbourne, Melbourne, VIC, Australia; ${ }^{21}$ Menzies Research Institute Tasmania, \\ University of Tasmania, Hobart, Australia; ${ }^{22}$ Australian Government Department of Health and Ageing, Canberra, ACT, Australia; ${ }^{23}$ Centre for \\ Rural and Remote Mental Health, University of Newcastle, Newcastle, NSW, Australia; ${ }^{24}$ School of Medicine, Pharmacy and Health, Durham \\ University, Durham, UK
}

Background. There are insufficient data from nationwide surveys on the prevalence of specific psychotic disorders and associated co-morbidities.

Method. The 2010 Australian national psychosis survey used a two-phase design to draw a representative sample of adults aged 18-64 years with psychotic disorders in contact with public treatment services from an estimated resident population of 1464923 adults. This paper is based on data from 1642 participants with an International Classification of Diseases (ICD)-10 psychotic disorder. Its aim is to present estimates of treated prevalence and lifetime morbid risk of psychosis, and to describe the cognitive, physical health and substance use profiles of participants.

Results. The 1-month treated prevalence of psychotic disorders was 3.10 cases per 1000 population aged 18-64 years, not accounting for people solely accessing primary care services; lifetime morbid risk was 3.45 per 1000 . Mean premorbid intelligence quotient was approximately 0.5 s.D.s below the population mean; current cognitive ability (measured with a digit symbol coding task) was 1.6 s.D.s below the population mean. For both cognitive tests, higher scores were significantly associated with better independent functioning. The prevalence of the metabolic syndrome was high, affecting $60.8 \%$ of participants, and pervasive across diagnostic groups. Of the participants, two-thirds (65.9\%) were current smokers, $47.4 \%$ were obese and $32.4 \%$ were sedentary. Of the participants, half $(49.8 \%)$ had a lifetime history of alcohol abuse/dependence and $50.8 \%$ lifetime cannabis abuse/dependence.

Conclusions. Our findings highlight the need for comprehensive, integrative models of recovery to maximize the potential for good health and quality of life for people with psychotic illness.

Received 21 August 2013; Revised 5 November 2013; Accepted 9 November 2013; First published online 2 January 2014

Key words: Bipolar disorder, schizo-affective disorder, schizophrenia, speed of information processing, substance abuse.

\footnotetext{
* Address for correspondence: V. A. Morgan, Ph.D., Neuropsychiatric Epidemiology Research Unit M571, School of Psychiatry and Clinical Neurosciences, The University of Western Australia, 35 Stirling Highway, Crawley 6009, WA, Australia.

(Email: vera.morgan@uwa.edu.au)
} 


\section{Introduction}

Psychotic illnesses comprise a heterogeneous group of disorders including schizophrenia, schizo-affective disorder, bipolar disorder with psychotic features, depression with psychosis and delusional disorders. Clinical onset of psychotic disorders occurs most often in late adolescence/early adulthood. These disorders are generally associated with persistent, or recurrent, and often disabling symptoms, and contribute substantially to the overall burden of years lived with disability (Vos et al. 2012). Recovery (symptom remission/reduction and functional improvement; Leucht \& Lasser, 2006) is possible. However, improving outcome and quality of life for people with psychosis requires more than amelioration of symptoms. Cognition is impaired in a significant proportion of people with schizophrenia and is a critical determinant of poor functional outcome (Green et al. 2000; Gold, 2004). Cognitive impairment may precede illness onset (Reichenberg et al. 2005; Khandaker et al. 2011), and intelligence quotient (IQ) tends to decline over the course of illness (Woodberry et al. 2008). It is also well established that physical morbidity, especially cardiometabolic disease, and premature mortality are elevated in this group (Lawrence et al. 2001; Saha et al. 2007). In schizophrenia, life expectancy is reduced by 18.7 years for men and 16.3 years for women, compared with the general population (Laursen, 2011), and the gap is widening (Saha et al. 2007; Lawrence et al. 2013; Nielsen et al. 2013). Diseases of the circulatory system influence life expectancy more than death from external causes (Laursen, 2011). Antipsychotic medication is likely to contribute to high rates of cardiometabolic disorders, both directly, as well as mediated through weight gain side effects (De Hert et al. 2011). However, metabolic disturbance was observed in severe mental illness well before the introduction of antipsychotic medication (Maudsley, 1879), pointing to other key causal factors including modifiable life-style risks (obesity, smoking, substance abuse, low levels of physical activity and poor nutrition). General population studies also report an association between metabolic disturbance and cognitive dysfunction (Brands et al. 2005; Gao et al. 2008), predominantly in older samples with diabetes. However, few studies have examined this relationship in people with psychosis. Some (Dickinson et al. 2008; Lindenmayer et al. 2012; Han et al. 2013), but not all (Meyer et al. 2005), studies support the association, but the direction of causality in a disorder where cognition may be impaired early in its course remains indeterminate. From a positive perspective, there is good evidence of the effectiveness of cognitive remediation and other non-pharmacological interventions in improving specific outcomes in psychotic disorders, including cognitive function (Wykes et al. 2011) and physical health (Verhaeghe et al. 2011; Daumit et al. 2013).

The prevalence of common mental disorders is well documented (Kessler et al. 2007). However, few studies (Perälä et al. 2007; Kodesh et al. 2012) have reported estimates for psychotic disorders other than schizophrenia (Saha et al. 2005), and most do not include co-morbidities. In addition to prevalence estimates of specific psychotic disorders and co-morbidities, we also need simultaneously collected descriptive data on disability and social circumstances. These data are critical to mapping the extent of burden experienced across psychotic disorders, as well as identifying correlates of good outcome, in order to inform policy development and service planning.

With these data deficits in mind, the aims of the second Australian national survey of psychosis in 2010 (Survey of High Impact Psychosis; SHIP) were to estimate treated prevalence of psychosis for people aged 18-64 years in contact with public mental health services, including services provided through publicly funded non-government organizations (NGOs), and to describe, for these individuals, their mental and physical health, cognitive and other functioning, substance use, and personal, social and living circumstances. This paper reports, for psychosis overall, and for its component disorders, estimated 1-month treated prevalence and lifetime morbid risk (LMR), and rates of co-existing phenomena, focusing on cognition, physical ill-health and substance abuse. In addition, we take advantage of this large, unbiased sample of individuals in contact with treatment services to (i) examine whether those with greater cognitive impairment have poorer functioning and are at increased risk of the metabolic syndrome, and (ii) calculate the independent contribution of modifiable life-style risk factors to cardiometabolic disease.

\section{Method}

\section{Population coverage}

The 2010 Australian psychosis survey took place at seven catchment sites in five Australian states, covering an estimated resident population aged 18-64 years of 1464923 people, approximately 10\% of Australians in that age range. The study sample comprised people aged 18-64 years, resident in the catchment sites and in contact with designated public mental health services (in-patient, out-patient, ambulatory and community mental health) and NGOs supporting people with mental illness. Detailed catchment profiles are available (Morgan et al. 2011). The census 
of people with psychosis was in March 2010. Interviews were conducted between April and December 2010.

\section{Design}

A two-phase design was employed (Pickles et al. 1995). In phase 1, a psychosis screener (Jablensky et al. 1999, 2000) was used to identify individuals likely to meet diagnostic criteria. In addition to censusmonth enumeration, administrative records were examined in order to identify individuals with psychosis who were in contact with public mental health services in the 11 months prior to census but not in the census month. There were 7955 people who screened positive for psychosis who met eligibility criteria. In phase 2, 1825 people who were screen-positive in phase 1 , and 164 who were screen-negative, were randomly selected, stratified by site and age group (18-34 years; 35-64 years) and interviewed. Data from the screen-negative group enabled estimation of prevalence without assuming that the psychosis screen had perfect sensitivity. The design and methodology have been described in full elsewhere (Morgan et al. 2011, 2012).

A 1-month treated prevalence was estimated per 1000 population aged 18-64 years by age strata and sex using sampling weights derived from phase 1 to phase 2 (Alonzo et al. 2003) and by expressing estimated numbers of persons in the screened population meeting diagnostic criteria as a proportion of the corresponding at-risk resident population of the catchment areas. LMR was estimated per 1000 population aged 18-45 years by sex using Weinberg's abridged method (Jablensky et al. 2011) (see online Supplementary Methods).

In the present study, descriptive data are for 1642 participants who were screen-positive for psychosis in phase 1 and who met full International Classification of Diseases (ICD)-10 criteria for a psychotic disorder in phase 2. Weighted estimates (see online Supplementary Methods) have been used.

\section{Key assessments}

Diagnostic classification. This was made using the Diagnostic Interview for Psychosis (DIP) (Castle et al. 2006). The DIP contains interview questions and probes, including items from the World Health Organization Schedules for Clinical Assessment in Neuropsychiatry (Wing et al. 1990) mapped onto the 90 diagnostic items of the Operational Criteria Checklist for Psychotic and Affective Illness (OPCRIT) (McGuffin et al. 1991). A computer algorithm provides diagnostic classification in accordance with ICD-10 and Diagnostic and Statistical Manual of
Mental Disorders, fourth edition (DSM-IV) criteria on the basis of the DIP ratings, thus reducing subjective bias in the interpretation of symptoms and signs. Inter-rater reliability was good (see online Supplementary Methods).

Physical health assessment. Physical health assessment including blood pressure, height, weight and waist circumference, was undertaken by trained staff following standardized procedures and using identical equipment (see online Supplementary Methods). Participants provided fasting venous blood samples for assays of plasma glucose, triglycerides, high-density lipoprotein cholesterol and total cholesterol concentrations; standard methods in accredited pathology laboratories were employed. The World Health Organization body mass index reference range (World Health Organization, 2000) was used to classify obesity. Physical activity in the past 7 days was rated using the International Physical Activity Questionnaire (Craig et al. 2003) and classified according to Australian Bureau of Statistics categories (Australian Bureau of Statistics, 2008). Harmonized criteria (Alberti et al. 2009) were used to determine the metabolic syndrome.

Cognitive assessment. This involved two brief tests: the National Adult Reading Test-Revised (NART-R; Nelson \& Willison, 1991) and the Digit Symbol Coding Test (DSCT) from the Repeatable Battery for the Assessment of Neuropsychological Status (Randolph, 1998). These tests provide reliable indices of cognitive ability prior to illness onset (NART-R) and currently (DSCT), and have been used extensively in previous studies of schizophrenia (Randolph, 1998; Smith et al. 1998; Crawford et al. 2001; Wilk et al. 2002; Dickinson et al. 2007). The NART-R Full-Scale IQ score was used to estimate premorbid IQ. The stability of NART-estimated intelligence over the longterm course of schizophrenia has been demonstrated (Morrison et al. 2000). The DSCT assesses cognitive processing efficiency. It requires the coordination and speeded performance of a range of simpler skills including: visual scanning, relational memory and motor ability. Lower coding scores signify relatively poorer performance, that is, greater information processing inefficiency. The DSCT is a robust indicator both of the presence and risk of illness (Dickinson et al. 2007) and functional outcome in schizophrenia (Gold et al. 2002).

Course of illness. Course of illness (single episode; multiple episodes of acute illness with partial/good recovery; continuous, chronic with/without deterioration) was assessed and rated by the interviewers 
who based their ratings on participant responses throughout the course of the interview.

Independent functioning. In the 4 weeks prior to interview, independent functioning was assessed by interviewers using the Multidimensional Scale of Independent Functioning (MSIF; Jaeger et al. 2003). Here we report on the Overall Global Independent Functioning scale which assessed functioning across occupational, educational and residential domains, correcting role functioning for degree of role responsibility, level of support provided, and actual performance: a score of 1 indicates functioning equivalent to community norms and 7 indicates total disability. The MSIF has been validated on samples of people with schizophrenia (Jaeger et al. 2003) and bipolar disorder (Berns et al. 2007) and has been used to assess the relationship between cognitive function and real-world outcomes in schizophrenia (Heinrichs et al. 2010). Since the MSIF does not measure sociability ('social drive'), this was rated independently for the past year by the interviewers on the basis of multiple items in the interview tapping into this domain.

\section{Data analysis}

Weighted analysis was done in IBM SPSS Modules for Complex Samples 21 (IBM, USA), which takes into account survey design and sampling weights. For the most part, population estimates are presented as percentages or means, with $95 \%$ confidence intervals (CIs). Conservatively, comparisons were considered statistically significant when CIs did not overlap (Julious, 2004). The SPSS Complex Samples General Linear Model was used to examine the association between cognition and cardiometabolic profile/ risk factors. Complex Samples Logistic Regression was used to model univariate and multivariate relationships between the metabolic syndrome and lifestyle risk factors. S.D.s of means were calculated using Stata/IC 12.0 survey commands (StataCorp LP, USA).

\section{Results}

The 1-month treated prevalence of psychotic disorders and lifetime estimate of morbid risk

The 1-month treated prevalence of psychotic disorders in public mental health services was 3.10 cases per 1000 population aged 18-64 years (Table 1). Schizophrenia/schizo-affective disorder was the most prevalent diagnosis, and twice as prevalent in males as females. Bipolar disorder with psychosis was the next most frequent diagnosis, occurring substantially less frequently than schizophrenia/schizo-affective disorder and at comparable rates in males and females. 
The prevalence of depressive psychosis and delusional disorders was relatively low. LMR rates (Table 1) were somewhat higher than prevalence estimates but with comparable patterns of occurrence and sex differences.

\section{The 12-month interviewed sample}

The number of people meeting ICD-10 criteria for a psychotic disorder was 1642 (weighted $n=7112$ ). Online Supplementary Tables S1-S14 include descriptive data on the interviewed sample by diagnostic group. The proportion of males was 61.1\% (range $39.7-70.4 \%$ across the five diagnostic groups). The mean age at onset was 24 years (range 23-25 years) and the mean age at interview was 39 years (range 39-42 years). Mean duration of illness was 16 years (range 15-17 years) (see online Supplementary Tables S1 and S3).

\section{Course of illness and functioning}

The majority of participants $(61.6 \%$ in total, range $54.8-77.6 \%$ across the diagnostic groups) were rated as having multiple episodes of illness with good or partial recovery between episodes (online Supplementary Table S3). For one-third (32.5\%), however, course of illness was continuous. The proportion was highest for schizophrenia (38.8\%) and lowest for bipolar disorder with psychosis $(18.9 \%)$; this difference was significant $(p<0.000)$. The mean score for global independent functioning was 3.5. The highest mean score (indicating poorest performance) was for schizophrenia and the lowest was for depressive psychosis (online Supplementary Table S9). Overall, one-quarter $(23.5 \%)$ of participants were rated as normal or very mildly disabled relative to community norms with respect to independent functioning while almost another quarter $(22.2 \%)$ were assessed as significantly, extremely or totally disabled. In addition, almost two-thirds $(65.1 \%)$ of participants were rated as having obvious or severe dysfunction in social drive. This figure was highest for depressive psychosis (79.4\%) and lowest for bipolar disorder with psychosis (58.1\%), a significant difference.

\section{Cognitive impairment}

The proportions of participants with valid NART-R and DSCT data were $84.7 \%$ and $88.7 \%$, respectively. Mean estimated premorbid IQ (NART-R), 98.0 (S.D.=11.3), was approximately 0.5 s.D.s below the population mean (Nelson \& Willison, 1991) of 107.4 (s.D.=17.1) (online Supplementary Table S5). Current cognitive ability (DSCT) was markedly impaired: participants had a mean score of 38.3 (S.D.=10.6), which is 1.6 s.D.s below the population mean (Australian
Table 2. Current cognitive function ${ }^{\mathrm{a}}$ by age group

\begin{tabular}{lll}
\hline $\begin{array}{l}\text { Age group, } \\
\text { years }\end{array}$ & $\begin{array}{l}\text { 2010 Australian } \\
\text { psychosis survey } \\
\text { Mean (s.D., 95\% CI) }\end{array}$ & $\begin{array}{l}\text { Australian } \\
\text { population norms } \\
\text { Mean (s.D.) }\end{array}$ \\
\hline $18-24$ & $41.7(11.0,39.1-44.2)$ & $59.9(9.6)$ \\
$25-34$ & $40.2(9.9,39.1-41.3)$ & $59.7(9.1)$ \\
$35-44$ & $38.7(9.8,37.6-39.9)$ & $55.5(8.3)$ \\
$45-54$ & $34.7(10.4,33.0-36.4)$ & $51.8(8.4)$ \\
$55-64$ & $33.6(11.2,31.6-35.6)$ & $48.1(8.9)$ \\
\hline
\end{tabular}

S.D., Standard deviation; CI, confidence interval.

${ }^{a}$ Based on speed of information processing using the Digit Symbol Coding Test (Randolph, 1998).

${ }^{\mathrm{b}}$ Australian Schizophrenia Research Bank (2011).

Schizophrenia Research Bank, 2011) of 54.2 (S.D.=9.8). DSCT raw scores were also examined as a function of age group (Table 2). In both the survey and Australian normative samples, younger age groups performed better than older age groups. However, mean scores for the youngest survey participants were significantly lower than those for all normative age groups, including the oldest. Each diagnostic group scored below the population mean on the NART-R, albeit within 1 s.D., ranging from 0.4 s.D.s (bipolar disorder with psychosis) to 0.7 S.D.s (delusional disorders) below the norm (online Supplementary Table S5). Participants with schizophrenia scored significantly lower than those with bipolar disorder. For the DSCT, each diagnostic group scored over 1 s.D. below the norm, ranging from 1.2 s.D.s (depressive psychosis) to 1.7 s.D.s (schizophrenia, schizo-affective disorder and delusional disorders) below the norm (online Supplementary Table S5). Participants with schizophrenia scored significantly lower than those with bipolar disorder or depressive psychosis. Finally, higher NART-R and DSCT scores were both significantly associated with lower (better) scores on global independent functioning [general linear model regression estimates of -1.2 (95\% CI -1.7 to -0.7$)$ and -2.7 (95\% CI -3.2 to -2.3$)$, respectively].

\section{Cardiometabolic disease and its risk factors}

Of participants who provided fasting blood samples ( $n=1155,70.3 \%$ of the total), $60.8 \%$ met harmonized criteria (Alberti et al. 2009) for the metabolic syndrome. The proportions meeting thresholds for each component of the metabolic syndrome, or in treatment for the component condition, were: increased abdominal adiposity, $84.2 \%$; reduced high-density lipoproteins, $58.1 \%$; elevated triglycerides, $55.5 \%$; elevated blood pressure, 54.4\%; and elevated glucose, 35.3\% (online Supplementary Table S4). The prevalence of the 
metabolic syndrome and its component criteria was comparable across the diagnostic groups.

Many participants had potentially modifiable lifestyle risk factors for cardiometabolic disease (online Supplementary Table S4). Two-thirds (65.9\%) were current smokers (males 70.3\%; females 59.0\%), consuming 21 cigarettes per day on average, with $40.1 \%$ of the total meeting criteria for high or very high nicotine dependence (Fagerström Test for Nicotine Dependence; Heatherton et al. 1991). Of the participants, one-third (32.4\%) was assessed as being sedentary in the last 7 days, with a further $63.6 \%$ recording low levels of activity. As many as $70.6 \%$ had one or fewer serves of fruit per day, while $48.1 \%$ had one or fewer serves of vegetables per day. In addition to $84.2 \%$ meeting the abdominal adiposity threshold for the metabolic syndrome, $47.4 \%$ had a body mass index in the obese range. Almost two-fifths (38.8\%) of participants reported weight gain associated with medication use: the mean reported gain over the previous 6 months was $9.5 \mathrm{~kg}$.

Table 3 shows the relationship between cognition and the metabolic syndrome. Lower current cognitive performance (DSCT) was significantly associated with having the metabolic syndrome and with meeting threshold levels for each of its criteria. By contrast, there were no significant associations between premorbid IQ (NART-R) and the same measures. Examining life-style risk factors, lower current cognitive performance was significantly associated with body mass index, smoking and physical activity level, but not with fruit and vegetable consumption. Lower premorbid IQ was significantly associated with smoking only.

Further analysis was undertaken to assess the independent contribution of modifiable life-style risk factors to the metabolic syndrome. In univariate analyses, current smoking, body mass index and activity level, but not vegetable or fruit consumption, were significant predictors. In the unadjusted multivariate model, current smoking and body mass index remained significant. These variables were retained and the model was adjusted for sex, age, illness duration and socio-economic status. Further adjustment was made for potential confounders, first separately for medication use, diagnostic classification and current cognitive ability, and then for the three potential confounders combined. The results were virtually unchanged in all models and none of the added variables was significant (see Table 4).

\section{Co-morbid substance abuse}

Almost half $(49.8 \%)$ of the participants had a lifetime history of alcohol abuse/dependence (males 57.2\%; females $38.0 \%$ ). The proportion was highest for delusional disorder (54.1\%) and lowest for schizo-affective disorder $(46.5 \%)$. Based on consumption over the past year, $17.0 \%$ of the total sample met criteria for hazardous drinking and $12.9 \%$ for harmful or dependent drinking (Alcohol Use Disorder Identification Test) (Babor et al. 2001). The proportion with current harmful or dependent drinking was highest for depressive psychosis (21.9\%) and lowest for schizophrenia (11.3\%). In addition, $50.8 \%$ had a lifetime history of cannabis abuse/dependence (males $60.2 \%$; females $36.2 \%$ ). The proportion was highest for schizophrenia $(54.1 \%)$ and lowest for depressive psychosis (40.5\%). Over the past year, $30.8 \%$ of all participants had been using cannabis; $11.9 \%$ were using it daily. People with schizophrenia were least likely to be using cannabis daily $(10.0 \%)$ and those with schizoaffective disorder were most likely (15.6\%) (see online Supplementary Tables S7 and S8).

\section{Discussion}

The 1-month treated prevalence estimate for psychosis in Australia is 3.10 per 1000 population aged $18-64$ years, while the LMR is estimated to be 3.45 per 1000 population aged $18-45$ years. These figures do not take into account people solely accessing primary care or private mental health services for their disorder, or not in contact with any treatment service. Mindful of the more restricted age range of the LMR, the Australian LMR estimate is relatively low compared with international estimates (median per 1000 =7.20, interquartile range=4.7-17.20) (Saha et al. 2005). Estimates from a nationally representative sample in Finland have reported a lifetime prevalence for psychotic disorders, a value usually lower than LMR, as high as 34.8 per 1000 (Perälä et al. 2007). In keeping with the relatively low prevalence of psychotic disorders, the estimates for the subtypes are also low compared with published estimates. In particular, the estimated LMR for bipolar disorder with psychosis was only 0.76 per 1000 . Since our survey was specifically designed to capture psychotic disorders rather than all mood disorders, the estimates apply to affective psychoses only, and represent a lower boundary.

In keeping with previous findings (Reichenberg et al. 2005; Khandaker et al. 2011), we found cognitive impairment in people with psychosis that preceded illness onset. The mean estimated premorbid IQ for the survey participants was approximately 0.5 s.D.s below the population mean, similar to results by Morrison et al. (2000) of 96.9 (S.D.=14, range 69-124), and to S.D.s of 0.4 and 0.5 below the population mean reported in two recent reviews (Woodberry et al. 2008; Khandaker et al. 2011). Our data also support the evidence of further cognitive impairment after 
Table 3. Cognitive function and metabolic parameters

\begin{tabular}{|c|c|c|c|c|}
\hline & \multicolumn{2}{|c|}{ Premorbid $\mathrm{IQ}^{\mathrm{a}}$} & \multicolumn{2}{|c|}{ Current cognitive function ${ }^{\mathrm{b}}$} \\
\hline & Mean & $F, p$ & Mean & $F, p$ \\
\hline \multicolumn{5}{|c|}{ Metabolic syndrome $^{c}$ and threshold criteria } \\
\hline \multicolumn{5}{|c|}{ Met criteria for the metabolic syndrome ${ }^{c}$} \\
\hline No & 98.5 & $F=0.1, p=0.717$ & 40.2 & $F=21.3, p=0.000$ \\
\hline Yes & 98.2 & & 36.9 & \\
\hline \multicolumn{5}{|l|}{ Abdominal obesity } \\
\hline No & 97.3 & $F=1.1, p=0.289$ & 39.8 & $F=4.3, p=0.039$ \\
\hline Yes & 98.2 & & 38.0 & \\
\hline \multicolumn{5}{|c|}{ Reduced high-density lipoprotein levels } \\
\hline No & 99.3 & $F=3.8, p=0.052$ & 39.5 & $F=9.5, p=0.002$ \\
\hline Yes & 97.8 & & 37.3 & \\
\hline \multicolumn{5}{|c|}{ Elevated triglyceride levels } \\
\hline No & 98.3 & $F=0.0, p=0.903$ & 39.6 & $F=13.9, p=0.000$ \\
\hline Yes & 98.4 & & 37.0 & \\
\hline \multicolumn{5}{|l|}{ Elevated glucose levels } \\
\hline No & 98.2 & $F=0.1, p=0.703$ & 39.2 & $F=12.6, p=0.000$ \\
\hline Yes & 98.5 & & 36.7 & \\
\hline \multicolumn{5}{|l|}{ Elevated blood pressure } \\
\hline No & 98.3 & $F=0.2, p=0.694$ & 39.7 & $F=20.6, p=0.000$ \\
\hline Yes & 98.0 & & 37.0 & \\
\hline \multicolumn{5}{|l|}{ Life-style risk factors } \\
\hline \multicolumn{5}{|l|}{ Current smoker } \\
\hline No & 100.1 & $F=20.2, p=0.000$ & 39.3 & $F=6.5, p=0.011$ \\
\hline Yes & 96.9 & & 37.6 & \\
\hline \multicolumn{5}{|l|}{ Body mass index } \\
\hline Underweight/normal & 97.7 & $F=0.4, p=0.690$ & 40.0 & $F=4.4, p=0.012$ \\
\hline Overweight & 98.5 & & 38.2 & \\
\hline Obese & 97.9 & & 37.6 & \\
\hline \multicolumn{5}{|l|}{ Level of physical activity } \\
\hline Very low & 98.1 & $F=0.2, p=0.903$ & 36.8 & $F=3.1, p=0.025$ \\
\hline Low & 98.0 & & 38.8 & \\
\hline Moderate & 97.6 & & 39.0 & \\
\hline High & 102.2 & & 39.3 & \\
\hline \multicolumn{5}{|c|}{ One or fewer serves of vegetables per day } \\
\hline No & 97.6 & $F=1.2, p=0.267$ & 38.2 & $F=0.1, p=0.802$ \\
\hline Yes & 98.4 & & 38.3 & \\
\hline \multicolumn{5}{|c|}{ One or fewer serves of fruit per day } \\
\hline No & 97.8 & $F=1.6, p=0.212$ & 38.3 & $F=0.2, p=0.688$ \\
\hline Yes & 98.7 & & 38.1 & \\
\hline
\end{tabular}

IQ, Intelligence quotient.

${ }^{a}$ Measured using the National Adult Reading Test-Revised (Nelson \& Willison, 1991).

${ }^{\mathrm{b}}$ Based on speed of information processing using the Digit Symbol Coding Test (Randolph, 1998).

${ }^{c}$ Based on harmonized criteria (Alberti et al. 2009).

illness onset (with DSCT scores slightly more than 1.5 S.D.s below the population mean) and of associated functional deficits, with both current and premorbid cognitive impairment related to poorer independent functioning. Finally, we found that current cognitive impairment, as measured by a speed of information processing task, was associated with cardiometabolic measures and life-style risk factors for cardiometabolic disease although we were unable to explore directionality in our cross-sectional data. The specific association with speed of information processing has been observed in general population studies (Brands et al. 2005), as well as schizophrenia studies (Dickinson et al. 2008; Lindenmayer et al. 2012). The pathophysiology underlying the association between metabolic dysregulation and cognition remains unclear. It is 
Table 4. Life-style risk factors and the metabolic syndrome

\begin{tabular}{|c|c|c|c|c|}
\hline & $\begin{array}{l}\text { Univariate } \\
\text { unadjusted odds } \\
\text { ratio }(95 \% \mathrm{CI})\end{array}$ & $\begin{array}{l}\text { Multivariate } \\
\text { unadjusted odds } \\
\text { ratio }(95 \% \mathrm{CI})\end{array}$ & $\begin{array}{l}\text { Multivariate } \\
\text { adjusted }^{\text {a }} \text { odds } \\
\text { ratio }(95 \% \mathrm{CI})\end{array}$ & $\begin{array}{l}\text { Multivariate } \\
\text { adjusted }^{\mathrm{b}} \text { odds } \\
\text { ratio }(95 \% \mathrm{CI})\end{array}$ \\
\hline \multicolumn{5}{|l|}{ Life-style risk factors } \\
\hline \multicolumn{5}{|l|}{ Currently a smoker } \\
\hline Yes & $1.3(1.0-1.7)^{*}$ & $1.9(1.4-2.6)^{*}$ & $2.2(1.6-3.0)^{*}$ & $2.3(1.6-3.2)^{*}$ \\
\hline No & Reference & Reference & Reference & Reference \\
\hline \multicolumn{5}{|l|}{ Body mass index } \\
\hline Underweight or normal & Reference & Reference & Reference & Reference \\
\hline Overweight & $4.8(3.2-7.2)^{*}$ & $5.3(3.5-8.0)^{*}$ & $5.3(3.5-8.2)^{*}$ & $4.9(3.1-7.8)^{*}$ \\
\hline Obese & $13.9(9.4-20.7)^{*}$ & $16.6(11.0-25.2)^{*}$ & $17.9(11.6-27.7)^{*}$ & $16.8(10.4-27.0)^{*}$ \\
\hline \multicolumn{5}{|l|}{ Activity level } \\
\hline Very low (sedentary) & $2.5(1.3-5.1)^{*}$ & - & - & - \\
\hline Low & $1.8(0.9-3.5)$ & - & - & - \\
\hline Moderate or high & Reference & - & - & - \\
\hline \multicolumn{5}{|c|}{ One or fewer serves of vegetables per day } \\
\hline Yes & $1.1(0.9-1.4)$ & - & - & - \\
\hline No & Reference & - & - & - \\
\hline \multicolumn{5}{|c|}{ One or fewer serves of fruit per day } \\
\hline Yes & $0.9(0.7-1.2)$ & - & - & - \\
\hline No & Reference & - & - & - \\
\hline
\end{tabular}

CI, Confidence interval.

${ }^{a}$ Adjusted for sex, age, illness duration and socio-economic status.

${ }^{\mathrm{b}}$ Adjusted for sex, age, illness duration and socio-economic status, and diagnosis, cognition and medication. $* p<0.05$.

likely to involve the joint effects of hyperglycaemia and hyperinsulinaemia increasing the risk of cerebral vascular abnormalities and structural brain changes either directly or mediated by mechanisms such as altered synaptic plasticity, oxidative stress, advanced glycation end-products and inflammation (Biessels et al. 2006; Panza et al. 2010; Jones, 2012). While an association has been reported between metabolic disturbance and cognitive deficits, including speed of processing deficits, in schizophrenia (Meyer et al. 2005; Lindenmayer et al. 2012), further investigation of possible bidirectionality is warranted in psychotic illness where cognitive impairment antedates the onset of metabolic disorders. In addition, cognitive impairment may exacerbate vulnerability for the metabolic syndrome via a variety of mechanisms including reduced responsiveness to public health measures targeting life-style risk factors.

Some $60.8 \%$ of participants met criteria for the metabolic syndrome, significantly higher than the prevalence of $32.5 \%$ for schizophrenia reported in a recent systematic review (Mitchell et al. 2013). Our prevalence is similar to the $54 \%$ reported for a clinical sample using more conservative International Diabetes Federation criteria (International Diabetes Federation, 2006) in one of a very few Australian studies (John et al. 2009), although another study found a $68 \%$ rate in a chronic, predominantly hospitalised, sample (Tirupati \& Chua, 2007). Our data underline the critical role of modifiable life-style risk factors for cardiometabolic disease, especially body mass index and smoking. It has been proposed that smoking cessation would produce a $75 \%$ reduction in high/very high risk of cardiovascular disease in people with schizophrenia (Bobes et al. 2010). Of concern, based on comparable subsamples from the 2010 and 1997-1998 national psychosis surveys, smoking rates had not changed over 13 years (Morgan et al. 2012). Cardiorespiratory fitness has also been associated with reduced all-cause mortality as well as mortality from cardiovascular disease (Wildgust \& Beary, 2010) and there is growing evidence for the mental health benefits of physical exercise (Erickson et al. 2011). However, 32.4\% of participants were sedentary and a further $63.6 \%$ recorded low levels of activity. Proportions for the Australian population in the same age range are $18.0 \%$ and 54.0\%, respectively (Morgan et al. 2011, 2012). We did not find that diet was related to the metabolic syndrome. A recent review of this area confirms that people with schizophrenia have a poor diet, but notes that evidence linking diet to metabolic abnormalities in this population is equivocal and further research is needed 
(Dipasquale et al. 2013). Intervention trials support the effectiveness of life-style modifications in this population (Verhaeghe et al. 2011; Daumit et al. 2013). Nonetheless, we need to know more about how best to promote, implement and support life-style changes in the community context, especially when the majority of our participants experience impaired social drive.

People with severe mental illness also face inequalities in physical health service delivery (Lawrence \& Kisely, 2010). We have previously reported that the proportion of survey participants having a blood test in the previous year had dropped markedly since the $1997-1998$ survey, from $83.1 \%$ to $64.8 \%$, while the proportion having had a physical examination had also dropped-from $79.6 \%$ to $66.1 \%$ (Morgan et al. 2012). Moreover, only half $(51.7 \%)$ of 2010 survey participants with hypertension were on medication for their condition; the figures for diabetes/hyperglycaemia and hypercholesterolaemia were even lower, at 39.8\% and 39.4\%, respectively (Galletly et al. 2012). These findings support the need for improved primary care interventions for this population, and the integration of general medical and mental health treatment (Jerrell et al. 2012).

Across the diagnostic groups, we observed some expected differences. Diagnostic groups differed in terms of course of disorder, symptom profiles, social drive (but not global independent performance) and psychotropic medication use. The finding of significantly lower premorbid IQ in schizophrenia compared with bipolar disorder with psychosis is consistent with the literature (Zammit et al. 2004). We also found that current cognitive ability, measured by a speed of information processing task, was significantly lower in schizophrenia compared with both bipolar disorder with psychosis and depressive psychosis. However, poor physical health was pervasive, as evidenced by high rates of the metabolic syndrome, of any of the threshold criteria for the metabolic syndrome or its modifiable life-style risk factors, and in the high prevalence of lifetime alcohol, cannabis and other substance abuse/dependence across all diagnostic groups.

\section{Strengths and limitations}

The 2010 Australian national survey of psychosis is one of the most comprehensive worldwide. Many of its 1500 data items have not previously been assessed contemporaneously and in such depth in a large, representative, national sample. The inclusion of the range of psychotic disorders in a sample of this size has enabled an assessment of the specificity of findings across the psychosis spectrum. The epidemiological sampling design ensures that findings are generalizable to adults in contact with public mental health treatment services in developed countries in similar public treatment service settings. We did not enumerate those solely in treatment in general medical practices or private psychiatric/psychological settings, or homeless people not in contact with any mental health services. We estimate that 1 -month prevalence would have risen from 3.1 to 5.3 per 1000 population, if we had accounted for these and those in the NGO sector (Morgan et al. 2012). In addition, we did not enumerate those in prison or forensic mental health services. Underestimation of prevalence may have occurred if people with psychosis were missed during screening, or if refusal/inability to participate was associated with a higher likelihood of illness exacerbation. However, comparison of screening data, including symptom profiles, between interviewed participants and those selected for interview but not participating for any reason, indicated no systematic selection biases. The impact of normal sampling variation, errors in population estimates and diagnostic misclassification is likely to be either negligible or to result in underestimation of prevalence.

\section{Conclusions}

People with psychosis continue to experience poor physical health, even though many of their risk factors are modifiable and despite public health campaigns aimed at these very risk factors. The World Health Organization has identified tobacco use, high blood pressure, overweight and obesity, physical inactivity, high blood glucose, high cholesterol, low fruit and vegetable intake, and alcohol use among the 10 top risks for mortality and disability in high-income countries (World Health Organization, 2009). Our survey found high rates of all eight risk factors among participants, with no significant differences between the diagnostic groups, highlighting urgent need for physical health interventions across the range of psychotic disorders. Moreover, the observed deficit in current cognitive function and its relationship with both physical health and global functioning suggests that cognitive remediation must be an integral component of intervention for people with psychotic illness, with important implications for workforce planning. At the same time, further investigation is warranted into who will have good mental and physical outcomes, and why. One-quarter of our participants had no or only mild impairment in global independent functioning, and two in five did not have the metabolic syndrome. Our data challenge services to establish comprehensive and integrative models of recovery in order to maximize the potential for good health and quality of life for all people with psychotic illness. 


\section{Supplementary material}

For supplementary material accompanying this paper, please visit http://dx.doi.org/10.1017/ S0033291713002973.

\section{Acknowledgements}

This paper is based on data collected in the framework of the 2010 Australian National Survey of High Impact Psychosis. The members of the Survey of High Impact Psychosis Technical Group were: V. A. Morgan (National Project Director), A. Jablensky (Chief Scientific Advisor), A. Waterreus (National Project Coordinator), R. Bush, V. Carr, D. Castle, M. Cohen, C. Galletly, C. Harvey, B. Hocking, A. Mackinnon, P. McGorry, J. J. McGrath, A. L. Neil, S. Saw, H. J. Stain. The site coordinators were A. Baker, L. Campbell, J. Green, J. Griffith, M. Hanlon, M. Haydock, L. Hayes, A. Poon and S. Sweeney. The interviewers were L. Anthes, N. Atkinson, F. Barclay, K. Barrack, L. Bates, A. Brown, R. Bush, I. Cairney, R. Caley, S. Dixon, L. Dixon, K. Douglas, L. Drinkwater, P. Edwards, V. Fenby, C. Harper, M. Heath, B. Hulse, E. Killen, L. Niven, D. Novello, D. Rich, G. Roddis, K. Scholes, S. Turner and J. Waterson. Population statistics from the 2007 National Survey of Mental Health and Wellbeing matching the psychosis survey age criteria were provided by Dr Tim Slade. Ethics approvals for the study were obtained from relevant institutional human research ethics committees. The study was funded by the Australian Government Department of Health and Ageing. We acknowledge, with thanks, the hundreds of mental health professionals and general practitioners who participated in the preparation and conduct of the survey and the many Australians with psychotic disorders who gave their time and whose responses form the basis of this publication.

This study was approved by institutional human research ethics committees at the seven study sites. All participants provided written, informed consent prior to participation. The authors assert that all procedures contributing to this work comply with the ethical standards of the relevant national and institutional committees on human experimentation and with the Helsinki Declaration of 1975, as revised in 2008.

This survey was funded by the Australian Government Department of Health and Ageing under contract to The University of Western Australia.

\section{Declaration of Interest}

D.C. has received grant monies for research from Eli Lilly, Janssen Cilag, Roche, Allergen, Bristol-Myers Squibb, Pfizer, Lundbeck, AstraZeneca and Hospira; travel support and honoraria for talks and consultancy from Eli Lilly, Bristol-Myers Squibb, AstraZeneca, Lundbeck, Janssen Cilag, Pfizer, Organon, SanofiAventis, Wyeth, Hospira and Servier; and is a current advisory board member for Lu AA21004 (Lundbeck), PRISTIQ $^{\circledR}$ (Pfizer), varenicline (Pfizer), asenapine (Lundbeck) and SEROQUEL ${ }^{\circledR}$ (AstraZeneca). He has no stocks or shares in any pharmaceutical company. Within the past 24 months P.M. has received investigator-initiated research grants from Janssen-Cilag and AstraZeneca, lecture payments from JanssenCilag and the Lundbeck Foundation, and consultancy fees from Roche. C.G. has undertaken clinical trials with Eli Lilly, Sunovian, Roche, Bristol-Myers Squibb, Lundbeck, Janssen-Cilag; has participated in advisory boards for Pfizer; and has received honoraria for speaking from MSD and AstraZeneca. J.J.M. declares the following: Lundbeck Schizophrenia Advisory Board for Saphis (asanepine) 2011-2012; AstraZeneca - honoraria for talks at Melbourne Clinic, Royal Melbourne Hospital, Eastern Health Sector, St Vincent's, Westmead Hospital 2012-2013; Eli Lilly - industry contribution to joint University of Queensland and Qhealth-funded Queensland Smart State Fellowship for Dr Xiaoying Cui (2009-2012).

\section{References}

Alberti KG, Eckel RH, Grundy SM, Zimmet PZ, Cleeman JI, Donato KA, Fruchart JC, James WP, Loria CM, Smith SC (2009). Harmonizing the metabolic syndrome: a joint interim statement of the International Diabetes Federation Task Force on Epidemiology and Prevention; National Heart, Lung, and Blood Institute; American Heart Association; World Heart Federation; International Atherosclerosis Society; and International Association for the Study of Obesity. Circulation 120, 1640-1645.

Alonzo TA, Pepe MS, Lumley T (2003). Estimating disease prevalence in two-phase studies. Biostatistics 4, 313-326.

Australian Bureau of Statistics (2008). National Survey of Mental Health and Wellbeing 2007. Catalogue no. 4326.0. Australian Bureau of Statistics: Canberra.

Australian Schizophrenia Research Bank (2011). Customised data provided by the Australian Schizophrenia Research Bank (http://www.schizophreniaresearch.org.au/bank/) which is supported by the National Health and Medical Research Council of Australia, the Pratt Foundation; Ramsay Health Care and the Schizophrenia Research Institute.

Babor TF, Higgins-Biddle JC, Saunders JB, Monteiro MG (2001). AUDIT. The Alcohol Use Disorders Identification Test. Guidelines For Use in Primary Care, 2nd edn. WHO/MSD/ 01.6a. World Health Organization: Geneva.

Berns S, Uzelac S, Gonzalez C, Jaeger J (2007). Methodological considerations of measuring disability in bipolar disorder: validity of the Multidimensional Scale of Independent Functioning. Bipolar Disorders 9, 3-10. 
Biessels GJ, Staekenborg S, Brunner E, Brayne C, Scheltens P (2006). Risk of dementia in diabetes mellitus: a systematic review. Lancet Neurology 5, 64-74.

Bobes J, Arango C, Garcia-Garcia M, Rejas J (2010). Healthy lifestyle habits and 10-year cardiovascular risk in schizophrenia spectrum disorders: an analysis of the impact of smoking tobacco in the CLAMORS schizophrenia cohort. Schizophrenia Research 119, 101-109.

Brands AM, Biessels GJ, de Haan EH, Kappelle LJ, Kessels RP (2005). The effects of type 1 diabetes on cognitive performance: a meta-analysis. Diabetes Care 28, 726-735.

Castle D, Jablensky A, McGrath J, Carr V, Morgan VA, Waterreus A, Valuri G, Stain H, McGuffin P, Farmer A (2006). The Diagnostic Interview for Psychoses (DIP): development, reliability and applications. Psychological Medicine 36, 69-80.

Craig CL, Marshall AL, Sjöström M, Bauman AE, Booth ML, Ainsworth BE, Pratt M, Ekelund U, Yngve A, Sallis JF, Oja P (2003). International Physical Activity Questionnaire: 12-country reliability and validity. Medicine and Science in Sports and Exercise 35, 1381-1395.

Crawford JR, Deary IJ, Starr J, Whalley LJ (2001). The NART as an index of prior intellectual functioning: a retrospective validity study covering a 66-year interval. Psychological Medicine 31, 451-458.

Daumit GL, Dickerson FB, Wang NY, Dalcin A, Jerome GJ, Anderson CA, Young DR, Frick KD, Yu A, Gennusa JV III, Oefinger M, Crum RM, Charleston J, Casagrande SS, Guallar E, Goldberg RW, Campbell LM, Appel LJ (2013). A behavioral weight-loss intervention in persons with serious mental illness. New England Journal of Medicine 368, 1594-1602.

De Hert M, Correll CU, Bobes J, Cetkovich-Bakmas M, Cohen D, Asai I, Detraux J, Gautam S, Moller HJ, Ndetei DM, Newcomer JW, Uwakwe R, Leucht S (2011). Physical illness in patients with severe mental disorders. I. Prevalence, impact of medications and disparities in health care. World Psychiatry 10, 52-77.

Dickinson D, Gold J, Dickerson F, Medoff D, Dixon L (2008). Evidence of exacerbated cognitive deficits in schizophrenia patients with comorbid diabetes. Psychosomatics 49, 123-131.

Dickinson D, Ramsey ME, Gold JM (2007). Overlooking the obvious: a meta-analytic comparison of digit symbol coding tasks and other cognitive measures in schizophrenia. Archives of General Psychiatry 64, 532-542.

Dipasquale S, Pariante CM, Dazzan P, Aguglia E, McGuire P, Mondelli V (2013). The dietary pattern of patients with schizophrenia: a systematic review. Journal of Psychiatric Research 47, 197-207.

Erickson KI, Voss MW, Prakash RS, Basak C, Szabo A, Chaddock L, Kim JS, Heo S, Alves H, White SM, Wojcicki TR, Mailey E, Vieira VJ, Martin SA, Pence BD, Woods JA, McAuley E, Kramer AF (2011). Exercise training increases size of hippocampus and improves memory. Proceedings of the National Academy of Sciences 108, 3017-3022.
Galletly CA, Foley DL, Waterreus A, Watts GF, Castle DJ, McGrath JJ, Mackinnon A, Morgan VA (2012). Cardiometabolic risk factors in people with psychotic disorders: The second Australian national survey of psychosis. Australian and New Zealand Journal of Psychiatry 46, 753-761.

Gao L, Matthews FE, Sargeant LA, Brayne C (2008). An investigation of the population impact of variation in $\mathrm{HbA1c}$ levels in older people in England and Wales: from a population based multi-centre longitudinal study. BMC Public Health 8, 54.

Gold JM (2004). Cognitive deficits as treatment targets in schizophrenia. Schizophrenia Research 72, 21-28.

Gold JM, Goldberg RW, McNary SW, Dixon LB, Lehman AF (2002). Cognitive correlates of job tenure among patients with severe mental illness. American Journal of Psychiatry 159, 1395-1402.

Green MF, Kern RS, Braff DL, Mintz J (2000). Neurocognitive deficits and functional outcome in schizophrenia: are we measuring the 'right stuff'? Schizophrenia Bulletin 26, 119-136.

Han M, Huang XF, Chen da C, Xiu M, Kosten TR, Zhang XY (2013). Diabetes and cognitive deficits in chronic schizophrenia: a case-control study. PLOS ONE 8, e66299.

Heatherton TF, Kozlowski LT, Frecker RC, Fagerström K-O (1991). The Fagerström Test for Nicotine Dependence: a revision of the Fagerström Tolerance Questionnaire. British Journal of Addiction to Alcohol and Other Drugs 86, 1119-1127.

Heinrichs RW, Ammari N, Miles AA, McDermid Vaz S (2010). Cognitive performance and functional competence as predictors of community independence in schizophrenia. Schizophrenia Bulletin 36, 381-387.

International Diabetes Federation (2006). The IDF Consensus Worldwide Definition of the Metabolic Syndrome. International Diabetes Federation: Brussels.

Jablensky A, McGrath J, Herrman H, Castle D, Gureje O, Morgan VA, Korten A, Harvey C (2000). Psychotic disorders in urban areas: an overview of the Study on Low Prevalence Disorders. Australian and New Zealand Journal of Psychiatry 34, 221-236.

Jablensky A, McGrath J, Herrman H, Castle D, Gureje O, Morgan VA, Korten A, on behalf of the Low Prevalence Disorders Study Group (1999). People Living with Psychotic Illness: An Australian Study 1997-98. National Survey of Mental Health and Wellbeing: Report 4. National Mental Health Strategy. Mental Health Branch, Australian Commonwealth Department of Health and Aged Care: Canberra (http://www.health. gov.au/internet/main/publishing.nsf/Content/ 7D5BDF162FA03C76CA257BF0001C1B7D/\$File/psych.pdf). Accessed 28 November 2013.

Jablensky AJ, Kirkbride JB, Jones PB (2011). The epidemiological horizon. In Schizophrenia (ed. D R. Weinberger and P. J. Harrison), pp. 185-225. Wiley-Blackwell: Oxford.

Jaeger J, Berns SM, Czobor P (2003). The multidimensional scale of independent functioning: a new instrument for 
measuring functional disability in psychiatric populations. Schizophrenia Bulletin 29, 153-168.

Jerrell JM, McIntyre RS, Black GB (2012). Economic grand rounds: economic costs of failure to monitor adverse effects of second-generation antipsychotics: an underestimated factor. Psychiatric Services 63, 202-204.

John AP, Koloth R, Dragovic M, Lim SC (2009). Prevalence of metabolic syndrome among Australians with severe mental illness. Medical Journal of Australia 190, 176-179.

Jones DT (2012). Neural networks, cognition, and diabetes: what is the connection? Diabetes 61, 1653-1655.

Julious SA (2004). Using confidence intervals around individual means to assess statistical significance between two means. Pharmaceutical Statistics 3, 217-222.

Kessler RC, Angermeyer M, Anthony JC, De Graaf R, Demyttenaere K, Gasquet I, De Girolamo G, Gluzman S, Gureje O, Haro JM, Kawakami N, Karam A, Levinson D, Mora MEM, Oakley Browne MA, Posada-Villa J, Stein DJ, Tsang CHA, Aguilar-Gaxiola S, Alonso J, Lee S, Heeringa S, Pennell B-E, Berglund P, Gruber MJ, Petukhova M, Chatterji S, Üstün TB, on behalf of the WHO World Mental Health Survey Consortium (2007). Lifetime prevalence and age-of-onset distributions of mental disorders in the World Health Organization's World Mental Health Survey Initiative. World Psychiatry 6, 168-176.

Khandaker GM, Barnett JH, White IR, Jones PB (2011). A quantitative meta-analysis of population-based studies of premorbid intelligence and schizophrenia. Schizophrenia Research 132, 220-227.

Kodesh A, Goldshtein I, Gelkopf M, Goren I, Chodick G, Shalev V (2012). Epidemiology and co-morbidity of severe mental illnesses in the community: findings from a computerized mental health registry in a large Israeli health organization. Social Psychiatry and Psychiatric Epidemiology 47, 1775-1782.

Laursen TM (2011). Life expectancy among persons with schizophrenia or bipolar affective disorder. Schizophrenia Research 131, 101-104.

Lawrence D, Hancock KJ, Kisely S (2013). The gap in life expectancy from preventable physical illness in psychiatric patients in Western Australia: retrospective analysis of population based registers. British Medical Journal 346, f2539.

Lawrence D, Holman C, Jablensky A (2001). Duty to Care. Preventable Physical Illness in People with Mental Illness. The University of Western Australia: Perth.

Lawrence D, Kisely S (2010). Inequalities in healthcare provision for people with severe mental illness. Journal of Psychopharmacology 24, 61-68.

Leucht S, Lasser R (2006). The concepts of remission and recovery in schizophrenia. Pharmacopsychiatry 39, 161-170.

Lindenmayer JP, Khan A, Kaushik S, Thanju A, Praveen R, Hoffman L, Cherath L, Valdez G, Wance D (2012). Relationship between metabolic syndrome and cognition in patients with schizophrenia. Schizophrenia Research 142, 171-176.

Maudsley H (1879). The Pathology of Mind. Macmillan: London.
McGuffin PC, Farmer A, Harvey I (1991). A polydiagnostic application of operational criteria in studies of psychotic illness. Development and reliability of the OPCRIT system. Archives of General Psychiatry 48, 764-770.

Meyer JM, Nasrallah HA, McEvoy JP, Goff DC, Davis SM, Chakos M, Patel JK, Keefe RS, Stroup TS, Lieberman JA (2005). The Clinical Antipsychotic Trials Of Intervention Effectiveness (CATIE) Schizophrenia Trial: clinical comparison of subgroups with and without the metabolic syndrome. Schizophrenia Research 80, 9-18.

Mitchell AJ, Vancampfort D, Sweers K, van Winkel R, Yu W, De Hert M (2013). Prevalence of metabolic syndrome and metabolic abnormalities in schizophrenia and related disorders - a systematic review and meta-analysis. Schizophrenia Bulletin 39, 306-318.

Morgan VA, Waterreus A, Jablensky A, Mackinnon A, McGrath J, Carr V, Bush R, Castle D, Cohen M, Harvey C, Galletly C, Stain H, Neil A, McGorry P, Hocking B, Shah S, Saw S (2011). People Living with Psychotic Illness 2010. Report on the Second Australian National Survey. Australian Government Department of Health and Ageing: Canberra.

Morgan VA, Waterreus A, Jablensky A, Mackinnon A, McGrath JJ, Carr V, Bush R, Castle D, Cohen M, Harvey C, Galletly C, Stain HJ, Neil AL, McGorry P, Hocking B, Shah S, Saw S (2012). People living with psychotic illness in 2010: The second Australian national survey of psychosis. Australian and New Zealand Journal of Psychiatry 46, 735-752.

Morrison G, Sharkey V, Allardyce J, Kelly RC, McCreadie RG (2000). Nithsdale schizophrenia surveys 21: a longitudinal study of National Adult Reading Test stability. Psychological Medicine 30, 717-720.

Nelson HE, Willison J (1991). National Adult Reading Test (NART): Test Manual, 2nd edn. NFER Nelson: Windsor, UK.

Nielsen RE, Uggerby AS, Jensen SOW, McGrath JJ (2013). Increasing mortality gap for patients diagnosed with schizophrenia over the last three decades - a Danish nationwide study from 1980 to 2010. Schizophrenia Research 146, 22-27.

Panza F, Frisardi V, Capurso C, Imbimbo BP, Vendemiale G, Santamato A, D'Onofrio G, Seripa D, Sancarlo D, Pilotto A, Solfrizzi V (2010). Metabolic syndrome and cognitive impairment: current epidemiology and possible underlying mechanisms. Journal of Alzheimer's Disease 21, 691-724.

Perälä J, Suvisaari J, Saarni S, Kuoppasalmi K, Isometsä E, Pirkola S, Partonen T, Tuulio-Henriksson A, Hintikka J, Kieseppä T, Härkänen T, Koskinen S, Lönnqvist J (2007). Lifetime prevalence of psychotic and bipolar I disorders in a general population. Archives of General Psychiatry 64, 19-28.

Pickles A, Dunn G, Vázquez-Barquero JL (1995). Screening for stratification in two-phase ('two-stage') epidemiological surveys. Statistical Methods in Medical Research 4, 73-89.

Randolph C (1998). Repeatable Battery for the Assessment of Neuropsychological Status (RBANS): Test Manual. Harcourt Brace and Company: San Antonio.

Reichenberg A, Weiser M, Rapp MA, Rabinowitz J, Caspi A, Schmeidler J, Knobler HY, Lubin G, Nahon D, 
Harvey PD, Davidson M (2005). Elaboration on premorbid intellectual performance in schizophrenia: premorbid intellectual decline and risk for schizophrenia. Archives of General Psychiatry 62, 1297-1304.

Saha S, Chant D, McGrath J (2007). A systematic review of mortality in schizophrenia: is the differential mortality gap worsening over time? Archives of General Psychiatry 64, 1123-1131.

Saha S, Chant DC, Welham JL, McGrath J (2005). A systematic review of the prevalence of schizophrenia. PLoS Medicine 2, e141.

Smith D, Roberts S, Brewer W, Pantelis C (1998). Test-retest reliability of the National Adult Reading Test (NART) as an estimate of premorbid IQ in patients with schizophrenia. Cognitive Neuropsychiatry 3, 71-80.

Tirupati S, Chua L-E (2007). Obesity and metabolic syndrome in a psychiatric rehabilitation service. Australian and New Zealand Journal of Psychiatry 41, 606-610.

Verhaeghe N, De Maeseneer J, Maes L, Van Heeringen C, Annemans L (2011). Effectiveness and cost-effectiveness of lifestyle interventions on physical activity and eating habits in persons with severe mental disorders: a systematic review. International Journal of Behavioral Nutrition and Physical Activity 8, 28.

Vos T, Flaxman AD, Naghavi M, Lozano R, Michaud C, Ezzati M, Shibuya K, Salomon JA, Abdalla S, Aboyans V, Abraham J, Ackerman I, Aggarwal R, Ahn SY, Ali MK, Alvarado M, Anderson HR, Anderson LM, Andrews KG, Atkinson C, Baddour LM, Bahalim AN, Barker-Collo S, Barrero LH, Bartels DH, Basáñez M-G, Baxter A, Bell ML, Benjamin EJ, Bennett D, Bernabé E, Bhalla K, Bhandari B, Bikbov B, Bin Abdulhak A, Birbeck G, Black JA,

Blencowe $\mathrm{H}$, Blore JD, Blyth F, Bolliger I, Bonaventure A, Boufous S, Bourne R, Boussinesq M, Braithwaite T, Brayne C, Bridgett L, Brooker S, Brooks P, Brugha TS, Bryan-Hancock C, Bucello C, Buchbinder R, Buckle G, Budke CM, Burch M, Burney P, Burstein R, Calabria B, Campbell B, Canter CE, Carabin H, Carapetis J, Carmona L, Cella C, Charlson F, Chen H, Cheng AT-A, Chou D, Chugh SS, Coffeng LE, Colan SD, Colquhoun S, Colson KE, Condon J, Connor MD, Cooper LT, Corriere M, Cortinovis M, Courville de Vaccaro KC, Couser W, Cowie BC, Criqui MH, Cross M, Dabhadkar KC, Dahiya M, Dahodwala N, Damsere-Derry J, Danaei G, Davis A, De Leo D, Degenhardt L, Dellavalle R, Delossantos A, Denenberg J, Derrett S, Des Jarlais DC, Dharmaratne SD, Dherani M, Diaz-Torne C, Dolk H, Dorsey ER, Driscoll T, Duber H, Ebel B, Edmond K, Elbaz A, Eltahir Ali S, Erskine H, Erwin PJ, Espindola P, Ewoigbokhan SE, Farzadfar F, Feigin V, Felson DT, Ferrari A, Ferri CP, Fèvre EM, Finucane MM, Flaxman $S$, Flood L, Foreman K, Forouzanfar MH, Fowkes FGR, Franklin R, Fransen M, Freeman MK, Gabbe BJ, Gabriel SE, Gakidou E, Ganatra HA, Garcia B, Gaspari F, Gillum RF, Gmel G, Gosselin R, Grainger R, Groeger J, Guillemin F, Gunnell D, Gupta R, Haagsma J, Hagan H, Halasa YA, Hall W, Haring D, Haro JM, Harrison JE, Havmoeller R, Hay RJ, Higashi H, Hill C, Hoen B, Hoffman H, Hotez PJ, Hoy D, Huang JJ, Ibeanusi SE,
Jacobsen $\mathrm{KH}$, James SL, Jarvis D, Jasrasaria R, Jayaraman S, Johns N, Jonas JB, Karthikeyan G, Kassebaum N, Kawakami N, Keren A, Khoo J-P, King CH, Knowlton LM, Kobusingye O, Koranteng A, Krishnamurthi R, Lalloo R, Laslett LL, Lathlean T, Leasher JL, Lee YY, Leigh J, Lim SS, Limb E, Lin JK, Lipnick M, Lipshultz SE, Liu W, Loane M, Ohno SL, Lyons R, Ma J, Mabweijano J, MacIntyre MF, Malekzadeh R, Mallinger L, Manivannan S, Marcenes W, March L, Margolis DJ, Marks GB, Marks R, Matsumori A, Matzopoulos R, Mayosi BM, McAnulty JH, McDermott MM, McGill N, McGrath J, Medina-Mora ME, Meltzer M, Mensah GA, Merriman TR, Meyer A-C, Miglioli V, Miller M, Miller TR, Mitchell PB, Mocumbi AO, Moffitt TE, Mokdad AA, Monasta L, Montico M, Moradi-Lakeh M, Moran A, Morawska L, Mori R, Murdoch ME, Mwaniki MK, Naidoo K, Nair MN, Naldi L, Narayan KMV, Nelson PK, Nelson RG, Nevitt MC, Newton CR, Nolte $S$, Norman $P$, Norman $R$, O’Donnell M, O'Hanlon S, Olives C, Omer SB, Ortblad K, Osborne R, Ozgediz D, Page A, Pahari B, Pandian J, Panozo Rivero A, Patten SB, Pearce N, Padilla RP, Perez-Ruiz F, Perico N, Pesudovs K, Phillips D, Phillips MR, Pierce K, Pion S, Polanczyk GV, Polinder S, Pope CA, Popova S, Porrini E, Pourmalek F, Prince M, Pullan RL, Ramaiah KD, Ranganathan $D$, Razavi H, Regan M, Rehm JT, Rein DB, Remuzzi G, Richardson K, Rivara FP, Roberts T, Robinson C, Rodriguez De Leòn F, Ronfani L, Room R, Rosenfeld LC, Rushton L, Sacco RL, Saha S, Sampson U, Sanchez-Riera L, Sanman E, Schwebel DC, Scott JG, Segui-Gomez M, Shahraz S, Shepard DS, Shin H, Shivakoti R, Singh D, Singh GM, Singh JA, Singleton J, Sleet DA, Sliwa K, Smith E, Smith JL, Stapelberg NJC, Steer A, Steiner T, Stolk WA, Stovner LJ, Sudfeld C, Syed S, Tamburlini G, Tavakkoli M, Taylor HR, Taylor JA, Taylor WJ, Thomas B, Thomson WM, Thurston GD, Tleyjeh IM, Tonelli M, Towbin JA, Truelsen T, Tsilimbaris MK, Ubeda C, Undurraga EA, van der Werf MJ, van Os J, Vavilala MS, Venketasubramanian N, Wang M, Wang W, Watt K, Weatherall DJ, Weinstock MA, Weintraub R,

Weisskopf MG, Weissman MM, White RA, Whiteford H, Wiersma ST, Wilkinson JD, Williams HC, Williams SRM, Witt E, Wolfe F, Woolf AD, Wulf S, Yeh P-H, Zaidi AKM, Zheng Z-J, Zonies D, Lopez AD, Murray CJL (2012).

Years lived with disability (YLDs) for 1160 sequelae of 289 diseases and injuries 1990-2010: a systematic analysis for the Global Burden of Disease Study 2010. Lancet 380, 2163-2196.

Wildgust HJ, Beary M (2010). Review: Are there modifiable risk factors which will reduce the excess mortality in schizophrenia? Journal of Psychopharmacology 24, 37-50.

Wilk CM, Gold JM, Bartko JJ, Dickerson F, Fenton WS, Knable M, Randolph C, Buchanan RW (2002). Test-retest stability of the Repeatable Battery for the Assessment of Neuropsychological Status in schizophrenia. American Journal of Psychiatry 159, 838-844.

Wing JK, Babor T, Brugha T, Burke J, Cooper JE, Giel R, Jablensky A, Regier D, Sartorius N (1990). 
SCAN: Schedules for Clinical Assessment in Neuropsychiatry. Archives of General Psychiatry 47, 589-593.

Woodberry KA, Giuliano AJ, Seidman LJ (2008). Premorbid IQ in schizophrenia: a meta-analytic review. American Journal of Psychiatry 165, 579-587.

World Health Organization (2009). Global Health Risks: Mortality and Burden of Disease Attributable to Selected Major Risks. World Health Organization: Geneva.

World Health Organization (2000). Obesity: Preventing and Managing the Global Epidemic. Report of a WHO Consultation.
WHO Technical Report Series no. 894. World Health Organization: Geneva.

Wykes T, Huddy V, Cellard C, McGurk SR, Czobor P (2011). A meta-analysis of cognitive remediation for schizophrenia: methodology and effect sizes. American Journal of Psychiatry 168, 472-485.

Zammit S, Allebeck P, David AS, Dalman C, Hemmingsson T, Lundberg I, Lewis G (2004). A longitudinal study of premorbid IQ score and risk of developing schizophrenia, bipolar disorder, severe depression, and other nonaffective psychoses. Archives of General Psychiatry 61, 354-360. 